\title{
“...The Way That You Do It": An Exploratory Study Investigating a Process- versus Outcome-Oriented Approach to School-Based Physical Activity Promotion
}

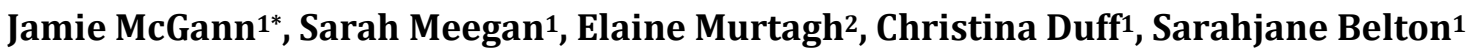 \\ ${ }^{1}$ School of Health and Human Performance, Dublin City University, Dublin, Ireland \\ ${ }^{2}$ Faculty of Physical Education and Sport Sciences, University of Limerick, Limerick, Ireland \\ Email: ^jamie.mcgann@dcu.ie
}

How to cite this paper: McGann, J., Meegan, S., Murtagh, E., Duff, C., \& Belton, S. (2020). “...The Way That You Do It": An Exploratory Study Investigating a Processversus Outcome-Oriented Approach to School-Based Physical Activity Promotion. Advances in Physical Education, 10, 262-281. https://doi.org/10.4236/ape.2020.103022

Received: July 6, 2020

Accepted: August 8, 2020

Published: August 11, 2020

Copyright $\odot 2020$ by author(s) and Scientific Research Publishing Inc. This work is licensed under the Creative Commons Attribution International License (CC BY 4.0).

http://creativecommons.org/licenses/by/4.0/

\begin{abstract}
Effectiveness of school-based physical activity (PA) initiatives is not only measured by short term impact on PA levels, but on modifiable determinants of PA such as perceptions and motivations towards PA engagement. These determinants predict more long-term effects and, when it comes to PA promotion, are potentially influenced not only by "what we do" but "the way that we do it". "The Active School Flag" is a whole school process-oriented physical activity initiative that aims to get more schools, more active, more often. In this exploratory study, a mixed methods research approach is taken to examine the differential impact of the Active School Flag compared to the outcome-oriented PA initiative "The Daily Mile" on measured PA and perceptions of PA, in Irish primary school children. Accelerometry data $(\mathrm{n}=$ 124; $41 \%$ girls) and focus group data $(\mathrm{n}=24 ; 50 \%$ girls) were collected from four schools of low socio-economic status at baseline and follow up (eight months later). Two schools implemented the Active School Flag initiative and two implemented the Daily Mile initiative. Contrasting trajectories in PA levels were observed over time with Daily Mile participants demonstrating a significant decrease in PA levels from baseline to follow up $(P=0.004)$, and Active School Flag participants demonstrating a significant increase $(P<0.001)$ over the same timeframe. This meant that while Daily Mile participants had significantly higher levels of PA at baseline compared to Active School Flag participants $(P<0.001)$, Active School Flag participants experienced a positive trajectory which saw them to "catch up" to TDM participants by follow up. From a qualitative perspective, 4 key themes, 1) Affordance of choice, 2) An appropriate level of challenge, 3) Importance of social interactions and 4) Belief
\end{abstract}


that an experience is of value were identified as underpinning participant's perceptions and motivations towards PA engagement. Themes were identified as more positively associated with Active School Flag participation compared to Daily Mile participation. Findings suggest that a process-oriented initiative, as opposed to an outcome-oriented initiative, presents as a more viable way of positively impacting children's PA levels, perceptions and motivations towards sustained PA engagement over time.

\section{Keywords}

Active Schools, Elementary Education, Health Promotions,

Self-Determination Theory, PA Interventions

\section{Introduction}

With the rising popularity of electronic media, children and adolescents now spend more than $60 \%$ of their 16-hour waking time in front of a screen and far less time engaged in physical activity (PA) (Barnett et al., 2018). In countries like Ireland and England, less than $20 \%$ of primary school children meet National Activity Guidelines (Woods et al., 2018; NHS, 2018) meaning this generation are particularly at risk of developing obesity, heart disease, stroke and diabetes in later life (Proudfoot et al., 2019; World Health Organisation, 2011). The school setting has been recognised as an important place to tackle this physical inactivity "crisis" (World Health Organisation, 2011; Department of Health and Social Care, 2018; Chalkley et al., 2018) and as such, there has been a dramatic increase in the number of school-based PA initiatives on offer to schools worldwide. Conversely, a meta-analysis by Love, Adams, \& van Sluijs (2019) found that many initiatives fail to support lasting change in PA behaviour beyond the school setting.

Research indicates that the effectiveness of a school-based PA initiative is dependent on a range of factors. For example, an initiative should be relatively easy to implement with fidelity, and to sustain over time (Grove, Zillich, \& Medic, 2014). In addition, an initiative should not only focus on positively impacting participant's in-school PA levels but also consider key modifiable determinants, such as perceptions of enjoyment and motivations towards PA engagement, which are more likely to result in children maintaining and increasing physical activity levels over time (Coulter \& Woods, 2011). Interestingly, these aforementioned factors are often impacted by specifics relating to an initiative's design. That is, some PA initiatives could be described as outcome-oriented; predominantly concerned with an end product or goal, and less concerned with the process of achieving that goal. An example of this would be where children are expected to run or walk for a prescribed distance or amount of time per day. Outcome-oriented initiatives often focus on directly replacing sedentary time with more structured opportunities for PA. They are typically appealing to educators for their simplicity (in terms of implementation), and their ability to pro- 
vide more immediate results (in terms of PA levels) (The Daily Mile, 2020). In contrast, other PA initiatives are designed to be more process-oriented, typically focused on a wider range of factors associated with PA engagement, rather than purely on the outcome of increased PA itself. For example these factors may include; quality physical education (PE), opportunities to develop movement competence, opportunities to engage with the wider school-community, etc. A process-oriented approach has more "parts", can take more time to embed and produce results, and may be perceived by educators as more challenging to implement (McGann et al., 2020).

A popular school-based PA initiative that can be described as more predominantly "outcome-oriented" is The Daily Mile (TDM) (2020). TDM is endorsed by the British Government as part of their childhood obesity plan (Department of Health and Social Care, 2018) and implemented in more than 4000 primary schools in the UK. TDM encourages children to take a break from the classroom and run or jog with their peers for fifteen minutes each day. The initiative identifies its "simplicity" as being one of its strengths with no staff training required, and no extra workload for teachers (Hanckel et al., 2019). Benefits of TDM participation listed by The Daily Mile Foundation (2020) include increased PA levels and physical fitness. Indeed, results of a small pilot study suggest the initiative supports positive physiological outcomes (e.g. increased PA and reduced sedentary time) (Chesham et al., 2018). That said, when these pilot study results were analysed more closely by Daly-Smith, Morris, Hobbs, \& McKenna (2019), it was noted that the PA levels of a significant number of TDM participants (45\%) actually decreased over time. This led Daly-Smith et al. (2019) to conclude, from a physiological perspective, that while the initiative may be effective for some, it is not effective for all. While The Daily Mile Foundation (2020) state that participation in TDM also supports "increased levels of enjoyment in PA", Breheny and colleagues (2020) point out that evidence which speaks to participant's psychological outcomes are largely anecdotal.

Active School Flag (ASF) is a popular primary school-based PA initiative that can be described as predominantly "process-oriented". Developed and implemented in schools across the Republic of Ireland, the ASF programme has a number of components or "parts" with a focus on provision of structured PE, opportunities for co-curricular PA, and developing community partnerships (The Active School Flag, 2020). Since its development in 2010, the ASF has reached more than 2000 primary schools across the Republic of Ireland. To date, research studies have highlighted that the ASF process provides a structure that supports development and change in the provision of PA for children (Ni Chróinín, Murtagh, \& Bowles, 2012), and increased enjoyment in PA experiences (McGann et al., 2020). While physiological outcomes associated with ASF have yet to be reported, as Daly-Smith et al. (2019) suggest, the act of committing time to being an "active school" and replacing sedentary activities with opportunities to be physically active means that ASF participation will likely lead to an increase in PA levels for at least some participants, during school time. 
As has previously been stated, research in the area of PA and health suggests that school-based PA initiatives can only have long-term effects where modifiable determinants of PA are positively supported. These include, among other things, participant's perceptions of enjoyment and motivation towards PA engagement (Coulter \& Woods, 2011). Recent literature provides empirical support for the use of Deci \& Ryan's (2011) Self-Determination Theory (SDT) as a means of evaluating these determinants and thus, the potential of a school-based PA initiative to support lasting behavioural change (Fortier et al., 2012). At a macro level, SDT proposes that there are two types of motivation which underlie human behaviour and prompt engagement in an activity or task. These are, intrinsic motivation, which refers to engagement for inherent reasons (i.e. a belief that an experience is enjoyable and/or of value) and extrinsic motivation, which refers to engagement primarily owing to a promise of rewards and recognition. At a more micro level, SDT proposes that individuals become more "self-determined" to engage in a behaviour when extrinsic motives become internalised. To that end, it is suggested that an internalisation process begins by meeting three basic psychological needs. These are: 1) autonomy-the need to feel that engagement in an activity is relatively self-endorsed and/or of value, 2) competence - the need to feel competent and confident to engage in an activity successfully, and 3) relatedness - the need to experience meaningful relationships and interactions with other people. Research suggests that if these three basic psychological needs can be fostered within a school-based PA initiative, participants are more likely to perceive physical activity as being enjoyable and of value, and more likely to be motivated to continue being physically active over time (Coulter \& Woods, 2011).

Accordingly, the current exploratory study takes a mixed methods research approach to investigate the differential impact of the ASF (process-oriented) and TDM (outcome-oriented) school-based PA initiatives on participant's PA levels, perceptions and motivations towards PA engagement, over a school year. Findings of this study are intended to further our understanding of the potential for these two different types of school-based PA initiatives to support lasting behavioural change.

\section{Methods}

This exploratory study presents a comparative design strategy where the effectiveness and advantages of one school-based PA initiative (ASF) are compared to another (TDM) without conceptualising either as being a formal control group (Basham, 1986). This type of strategy supports a thorough evaluation of an intervention process (Basham, 1986). The data collection process takes a mixed methods approach (accelerometry and focus groups) with quantitative data speaking to measured PA levels of participants, and qualitative data predominantly speaking to participants perceptions and motivations towards PA engagement. 


\subsection{Sampling, Recruiting and Timetable}

As part of a larger study, two co-educational schools from the Republic of Ireland were recruited by the researchers at an ASF information meeting held at the beginning of the school year (2018-2019). These two schools, who were both about to begin implementation of the ASF initiative, were then pair matched with two other co-ed schools of similar size and from similar locations who had never engaged with the ASF process. Pair matched schools were recruited by the researchers via email using contact information available on school websites. Initial discussions of the study with principals of pair matched schools revealed that whilst their schools had never implemented the ASF initiative, they had recently began implementing TDM. This afforded a unique opportunity, as a sub study within the larger study, to carry out a comparison of the impact that these two popular PA initiatives (the outcome-oriented TDM and the process-oriented ASF) have on PA levels and perceptions of PA, of Irish primary school children. As such, the research presented in the current paper emerged organically.

All schools in this exploratory study were of low socio-economic status and part of the Irish Department of Education's DEIS (Delivering Equality of Opportunity in Schools) programme which aims to address the educational needs of children from disadvantaged communities. There is strong evidence to suggest that children from disadvantaged communities are significantly less active than their socially advantaged peers (Love, Adams, Atkin, \& van Sluijs, 2019). Thus, the profile of participants in this study afforded additional insight into the potential effectiveness of school-based PA initiatives on measurement of PA and perceptions of PA of children deemed particularly in need of behavioural change.

Participants were recruited from $3^{\text {rd }}$ class (children aged $8-10$ years) and from $5^{\text {th }}$ class (children aged $10-12$ years) at each school. Specifics relating to the age, sex as well as the number of participants who contributed quantitative and qualitative data at both time points are outlined in Table 1. Baseline data were collected from all schools in the first 2 weeks of October (2018), with follow up data collected from all schools, 8 months later, in the first 2 weeks of June (2019).

Table 1. Mean age and number of ASF and TDM participants (overall and by sex) who contributed quantitative and qualitative data at baseline and follow up.

\begin{tabular}{ccccc}
\hline & \multicolumn{3}{c}{ Accelerometry Data } \\
\hline Initiative & Mean Age & Girls & Boys & Overall \\
TDM Schools & 10.3 yrs & 23 & 34 & 57 \\
ASF Schools & 10.1 yrs & 28 & 39 & 67 \\
& & & $\mathrm{~N}=124$ \\
\hline TDM Schools & 10.5 yrs & Focus Group Data & 12 \\
ASF Schools & 10.2 yrs & 6 & 6 & 12 \\
& & 6 & 6 & $\mathrm{~N}=24$ \\
\hline
\end{tabular}


Full approval for this study was given by the Dublin City University Research Ethics Committee (DCUREC/2018/168) with informed assent requested and granted by participants, and informed consent requested and received from school principals, participants and participant's parent(s)/guardian(s).

\subsection{Measures}

\subsubsection{Quantitative Data: Physical Activity Levels}

One hundred and twenty-four children provided accelerometry data (via ActiGraph GT1M and GT3X) at both points of this study. Sixty-seven children from ASF schools (42\% girls), 57 children from TDM schools (40\% girls). Accelerometers were validated for children and youth population (Hänggi, Phillips, \& Rowlands, 2013) and set at 10 second epochs to capture intermittent activity characteristic of children (Kim, Beets, \& Welk, 2012). At each school, two researchers demonstrated to participants, in groups of five, how to put on and adjust the accelerometer belt (over the iliac crest of the right hip) and assisted participants with adjusting the belt to fit correctly. Devices were labelled with a number and the participant's name to ensure that the correct/same device was worn each day. Participants were instructed to put on the belt on arrival to school in the morning and to take it off before going home each day, for a total of five days. Participants were also instructed to take the belt off for swimming or contact sports. Each participant was given a printed leaflet with these instructions. Accelerometers were collected by a member of the research team at the end of the five-day period for download and data processing.

Accelerometer data were processed using ActiLife software version 6.13.3. Data from the $y$-axis was used as it has been shown to be comparable across monitors (Sasaki, John, \& Freedson, 2011). The first and last day of wear were excluded and wear criteria for three days of at least five hours (between school hours of 9 am and 2:30 pm) was applied (Yli-Piipari et al., 2016). Non wear time was defined as 20 minutes of consecutive zeroes which is the most commonly used nonwear definition in children (Cain et al., 2013). Wear criteria was met by 67 ASF participants (44\% girls) and 57 TDM participants (43\% girls) across both timepoints. Evenson cut points (Evenson et al., 2008) were used to estimate average time spent in MVPA (in minutes) per school day ( $\geq 1951 \mathrm{CPM})$ at baseline and follow up.

\subsubsection{Qualitative Data: Perceptions of PA}

In total, 24 children participated in focus groups across the school year, with 23 of those children participating at both time points (further detail in Table 1). Focus groups lasted between 35 - 40 minutes at each school. Home-school liaison Officers (HSLO) at each school were asked to support recruitment of focus group participants using the following criteria; 1 ) number. three children from $3^{\text {rd }}$ class and three from $5^{\text {th }}$ class, 2) sex: an equal number of boys and girls, 3) additional traits. it was requested that at least three participants in each group could be classed as having poor attendance (i.e. absent between 20 - 30 days the previous school year) and/or poor punctuality (i.e. recorded as "late" on the school at- 
tendance system between 20 - 30 times the previous school year). These criteria were used to ensure a balanced sample of participants from each group and thus, representative data. Children who demonstrated characteristics of disengagement with school (e.g. poor punctuality/poor attendance) were recruited to provide valuable insight into the effectiveness of school-based PA initiatives from the perspective of children rarely heard from in the literature, i.e. those representing the most "at risk" group of being physically inactive across the life course.

An interview guide was developed with open-ended questions and probes to get an understanding of perceptions of physical activity and motivations towards physical activity engagement of participants in both ASF and TDM initiatives. The research team made the decision to avoid asking direct questions about either initiative as it was thought children could potentially believe the researchers to be representatives from ASF or TDM and feel compelled to answer questions in a "certain way" (e.g. to speak highly of an initiative, PE or PA), potentially skewing the data. Instead, interview questions (outlined in Table 2) focused on perceptions, feelings, attitudes and experiences of PA, sport, PE and school. The rationale for including questions on PE and school came from the literature, with research indicating that a child's feelings towards school ("school day affect") and their experiences of PE, can influence perceptions of PA. Put simply, social environmental factors such as positive relationships with teachers and peers, and the provision of $\mathrm{PE}$ that fosters actual and perceived movement competence and confidence, can have a significant impact on perceptions of enjoyment and ultimately, motivations towards PA engagement (Coulter \& Woods, 2011).

The focus group moderator was a male postdoctoral researcher who had significant experience as a primary/elementary teacher in schools of low SES status. Questions were piloted prior to the beginning of the research period in September 2018.

\subsection{Data Analysis}

\subsubsection{Quantitative Data}

Descriptive statistics were produced on the PA variable between the two groups and subgroups (sex) across time. A mixed-model ANOVA with repeated measures was also deployed. Effects of Time (baseline vs follow up), Group (TDM vs ASF) and interaction effects between Time $\times$ Group were identified. The specific PA variable used in this study was average number of minutes in MVPA (per school day). Quantitative data was processed, screened for normality and analysed using SPSS.

Table 2. Focus group questions that guided discussion.

Question 1: What is your favourite subject in school?

Question 2: What do you think about PE in school?

Question 3: Do you do any physical activities or sports outside of school?

Question 4: What is the best thing about going to school?

Question 5: Are there things you don't enjoy about school? 


\subsubsection{Qualitative Data}

Focus groups were audio recorded, transcribed verbatim and analysed through a systematic and rigorous process, grounded in reflexive Thematic Analysis (TA) (Braun \& Clarke, 2006). This took a five phased approach which included familiarisation with the data, coding of the data, searching for and reviewing data themes, defining and naming these themes and, production of a final report. Data were read several times to support a familiarisation of its contents, then coded to capture the nature of the comments made during the focus group discussion. Codes were examined across the entire data set to identify patterns of similarities, before identifying preliminary themes and sub-themes. The research team then reviewed the data once more, and final themes and sub-themes were agreed upon. It is important to note that themes were not merely found in the data or did not simply emerge from the data but were rather identified as stories about the data. These stories were informed by both the data itself and the researchers' theoretical assumptions, analytic resources and skill (Braun \& Clarke, 2019). In all, qualitative results presented in this paper have arisen from engagement with data as well as reflexive and thoughtful engagement with the analytic process.

\section{Results}

\subsection{Physical Activity Levels}

Sixty-seven children from ASF schools (42\% girls) and 57 children from TDM schools ( $40 \%$ girls) provided accelerometry data for this study (Table 1). Descriptive statistics on the PA variable between the two groups over time are presented. This PA variable represents average number of minutes spent in MVPA (per school day). Results (illustrated in Table 3) indicate that the PA levels of ASF and TDM schools experienced contrasting trajectories across time, with TDM schools demonstrating high levels of $\mathrm{PA}$ at baseline $(\mathrm{M}=34.5, \mathrm{SD}=11.4)$, but decreasing significantly by follow up $(\mathrm{M}=28.7, \mathrm{SD}=8.2 ; P=0.004)$. By comparison, ASF schools demonstrated low levels of $\mathrm{PA}$ at baseline $(\mathrm{M}=18.5, \mathrm{SD}=$ 6.9) but improved significantly at follow up $(\mathrm{M}=29.9, \mathrm{SD}=9.8 ; P=0.001)$.

Table 3. Changes in the PA variable (average minutes of MVPA per school day) of ASF and TDM participants by group and by sex, from baseline to follow up (8 months).

\begin{tabular}{|c|c|c|c|c|c|c|c|c|}
\hline Pair No. & ID & $\begin{array}{l}\text { Time } \\
\text { point }\end{array}$ & $\begin{array}{c}\text { All } \\
\text { Mean }\end{array}$ & Sig. & $\begin{array}{l}\text { Girls } \\
\text { Mean }\end{array}$ & Sig. & $\begin{array}{l}\text { Boys } \\
\text { Mean }\end{array}$ & Sig. \\
\hline \multirow{2}{*}{ Pair 1} & ASF & 1 & 18.5 & \multirow{2}{*}{0.000} & 15.7 & \multirow{2}{*}{0.000} & 20.6 & \multirow{2}{*}{0.000} \\
\hline & TDM & 1 & 34.5 & & 28.3 & & 38.4 & \\
\hline \multirow{2}{*}{ Pair 2} & ASF & 2 & 29.9 & \multirow{2}{*}{0.50} & 27.9 & \multirow{2}{*}{0.23} & 30.8 & \multirow{2}{*}{0.74} \\
\hline & TDM & 2 & 28.7 & & 25.4 & & 30.4 & \\
\hline \multirow{2}{*}{ Pair 3} & ASF & 1 & 18.5 & \multirow{2}{*}{0.000} & 15.7 & \multirow{2}{*}{0.000} & 20.6 & \multirow{2}{*}{0.000} \\
\hline & ASF & 2 & 29.9 & & 27.9 & & 30.8 & \\
\hline \multirow{2}{*}{ Pair 4} & TDM & 1 & 34.5 & \multirow{2}{*}{0.004} & 28.3 & \multirow{2}{*}{0.22} & 38.4 & \multirow{2}{*}{0.000} \\
\hline & TDM & 2 & 29.6 & & 25.4 & & 30.4 & \\
\hline
\end{tabular}

*Time point 1 refers to baseline, time point 2 refers to follow up ( 8 months later) output mean refers to average number of minutes in MVPA per school day. 
A mixed ANOVA with repeated measures was conducted to test for significant differences in the PA variable (average minutes in MVPA, per school day) between groups (ASF and TDM) and across time (baseline and follow up). A significant effect was observed relating to Time: $F(2,122)=9.24, P=0.003$, partial $\eta^{2}=0.07$, and Group: $F(2,122)=25.68, P<0.001$, partial $\eta^{2}=0.17$. A significant interaction effect between Time $\times$ Group: $F(2,122)=80.21, P<0.001$, partial $\eta^{2}=0.45$, was also observed, indicating that the effect of group on the PA variable was impacted by the time at which PA was measured. Results suggest that while the contrasting trajectories of PA levels of the two groups (ASF and TDM schools) meant that TDM schools demonstrated significantly higher levels of PA in comparison to ASF schools at baseline $(P<0.001)$, Active School flag participants experienced a more positive trajectory over time, effectively "catching up" with TDM participants and ultimately, no significant differences were observed between the two groups at follow up $(P=0.50)$ (Figure 1).

\subsection{Perceptions of PA}

Thematic analysis of focus group data identified four themes as having an influence on children's perceptions of PA as well as perceptions of determinants of PA engagement i.e. PE and school affect. These four themes were: i) Affordance of choice, ii) An appropriate level of challenge (not too difficult, not too easy), iii) Importance of social interactions and, iv) Belief that an experience has value. Focus group results are presented below, by theme and time point.

\subsubsection{Affordance of Choice}

"Affordance of choice" was identified as an influential factor on participant's perceptions of PA and PE at baseline. That is, when asked to share their thoughts about PE in school, most participants across all groups $(n=15)$ described affordance of choice as impacting perceptions (particularly perceptions of enjoyment) of physical education.

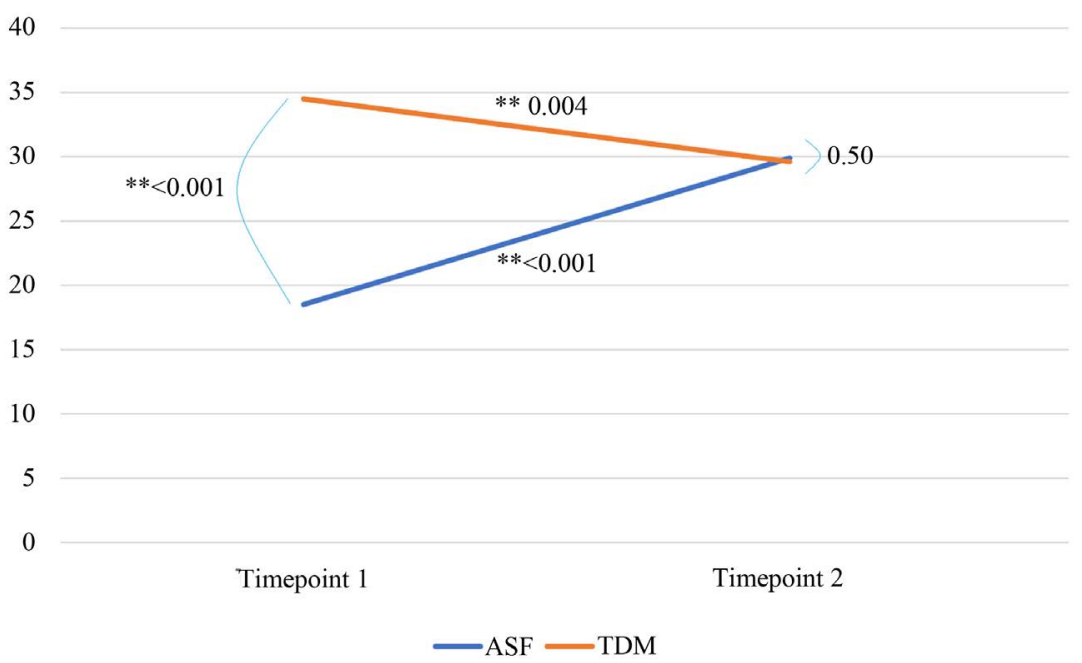

Figure 1. Trajectories of PA for ASF and TDM participants over time. ${ }^{* *}$ denotes a statistically significant difference. 
I like [PE]. I like dodge ball and we play that when it's up to the class to [choose] the activity. (Boy, ASF school, baseline)

I don't mind PE but like, we do the same things over and over, whatever the teacher [decides] and that's [disappointing]. (Girl, ASF school, baseline)

I don't like [PE]. We have to do the running, you don't actually have a choice and you have to keep going no matter what. (Girl, TDM school, baseline)

At follow up, 8 months later, affordance of choice was, once more, commonly discussed by participants $(n=13)$ across groups. Most participants in ASF focus groups $(n=7)$ discussed being afforded a level of choice in PE, while most TDM participants $(n=6)$ discussed a lack of choice relating to their PE experiences.

I like [PE]. I actually like that we do different things and not the same things. We do something for a few weeks.... now, we are doing "dancing", [before that] it was something else... jumping and throwing [athletics]. (Boy, ASF group, follow up)

[PE] is alright. It's better when we get to pick [the activity] but most of the time we don't do the normal PE because we don't have time and we have to do our [Daily Mile]... it's a bit, “...do we have to do it again?”. (Boy, TDM group, follow up)

"Affordance of choice" was also identified as influencing children's perceptions towards PA and PA engagement across all focus groups and both time points. When asked to share their experiences of physical activity engagement outside of school, most participants $(n=13)$ described how the affordance of choice influenced their perceptions of enjoyment.

I like to play on my scooter... [I like it] because you can go more places ...be a bit free.....and you don't just have to stay on your road. (Boy, TDM group, baseline)

I [enjoy] dancing. Most of the time [I dance] with my friends in our houses ....we like to just make up our own dances and come up with our own things. (Girl, ASF group, baseline)

At follow up, ASF participants were identified as demonstrating increased knowledge and understanding in relation to the choices of PA and sport on offer to them in the community/beyond the school setting. To that end, most ASF participants $(n=8)$ and some TDM participants $(n=4)$ discussed being involved in organised after-school PA or sports clubs.

People came in [to the school] from dancing and gymnastics........and football and ......you find out about things you can join....some of them are free. (Boy, ASF group, follow up)

\subsubsection{Appropriate Level of Challenge (Not Too Difficult, Not Too Easy)} Many participants across all groups $(\mathrm{n}=12)$ discussed an appropriate level of challenge (not too difficult, not too easy) as an additional factor which influenced perceptions of PE. 
I like PE because you don't have to do any work. It's not hard on your brains like, say, maths. (Boy, ASF group, baseline)

We do the [Daily Mile] for PE and I don't mind it because basically, when you get too tired, you can just walk. (Boy, TDM group, baseline)

For our PE so far we just [go] swimming and I don't like it because I can't actually swim. It's [hard] and a bit embarrassing. (Boy, ASF group baseline) We do the [Daily Mile] and it's just "no". You get really [tired] and then you're tired for the whole day, or most of the day. (Girl, TDM group, baseline)

At follow up, participants $(\mathrm{n}=5)$ in ASF groups discussed experiencing an appropriate level of challenge during PE.

PE is fun..... There's [usually] something that you're good at [and the] things that you're not great at, but like, you get better if you keep at it for a bit.... I [have become] good at [soccer] when I was [not competent] at the start of the year. (Boy, ASF group, follow up)

In contrast, more children in TDM groups $(n=6)$, equating The Daily Mile with PE (despite this not being the intention of the initiative), referenced an inappropriate level of challenge in relation to their experiences of physical education.

For our PE, we do the [Daily Mile] and it's just a bit boring...you do the same thing... and when you get [tired], if you stop, teacher shouts at you.

(TDM School 2)

Perceptions of enjoyment towards participation in PA and/or involvement in sports clubs outside of the school setting were also identified as being influenced by an appropriate level of challenge by participants across all groups at both time points.

I [take part in] gymnastics. I got my front handspring a few weeks ago and I just like it when you can't do something [in the beginning] but learn it after a while. (Girl, ASF group, baseline)

I was in Irish dancing but the teacher changed and we [kept] doing the same dances over and over again ....it was basically too easy......you're not learning anything new.....so I quit. (Girl, TDM group, baseline)

\subsubsection{Importance of Social Interactions}

"Importance of social interactions" was identified as a third theme which influenced participant's perceptions towards PE, PA and sport. In relation to PE, participants across both groups and both time points discussed how social interactions had both a positive and negative impact on their PE experiences.

I actually hate it in PE, when no one picks you and you feel stressed because basically, you suck. (Girl, ASF group, baseline)

What I like about PE is that you can play with [your] friends and have fun with [your] friends together. (Boy, ASF group, follow up) 
PE is good for actually being able to play with your friends and talking to them. You can talk to your friends while you're doing the running even. (Girl, TDM group, baseline)

When everyone's finished and they are all waiting for you, [because] you're dead last. That's [feels] so bad. (Girl, TDM, follow up)

"Importance of social interactions" was also identified as being an influential factor in relation to participant's perceptions of PA and PA engagement beyond the school setting across all three groups at both time points.

I like playing games after school because... sometimes you make friends when you play games like "chasing'. Someone new might be on your team and they tell you their name and then they might be your friend, then you have a new friend. (Boy, TDM group, baseline)

I was in a club but then my friend [quit] so, I didn't want to do it anymore on my own. (Girl, ASF group, follow up)

\subsubsection{Belief That an Experience Has Value}

A fourth theme, "Belief that an experience has value" was identified as influencing participants perceptions towards PE, PA and sport. This theme was rarely discussed at baseline across groups $(n=3)$ in relation to PE. However, perceptions were identified as having shifted at follow up, with "value" discussed by many ASF participants $(n=7)$ and some TDM participants $(n=2)$.

$\mathrm{PE}$ is good [because]... it gets your blood flowing and healthy [for you]. (Boy, TDM group, follow up)

In $[\mathrm{PE}]$ we learn how to check your heartbeat... your pulse... and get to know your muscles and why PE is healthy for you. (Girl, ASF group, follow up)

Similarly, "belief that an experience has value" was also identified as being associated with participant attitudes towards PA and sport, particularly at follow up. To that end, knowledge and understanding around the benefits of engagement in PA was identified in many ASF participants $(n=8)$ and some TDM participants $(\mathrm{n}=2)$ at follow up.

I like playing outside because you get the sun on your face and that gives you vitamins and it's good for me body... it also helps [me to] feel all relaxed. (Girl, ASF group, follow up)

My uncle was a pro boxer all his life and it took him [around] the world. I decided I would try it too. Then I was good at it, [like my] uncle, and I've stuck at it. (Boy, ASF group, follow up)

When discussing perceptions of PA and sport at follow up, one participant from an ASF group was identified as being influenced by all aforementioned factors and themes.

Loads of us do the running [club]... it's in the park beside the school... even the [mums and dads] go. You get a high-v is vest, you do [a] few laps, 
whatever you can, and you can time yourself and all. [The club] was on the telly... getting everybody fit again... running is important to get your heart being looked after... so that you're feeling better about yourself and in your head. You need to look after yourself... [and] your body. (Boy, ASF group, follow up)

\subsubsection{Perceptions of School: Influence of All Themes}

Research indicates that the way a child feels about school ("school day affect") can have significant influence on perceptions of physical activity engagement (Coulter \& Woods, 2011). Focus groups results in this study identified the aforementioned four themes as being influential factors of children's perceptions, and particularly perceptions of enjoyment, towards school. For example, when asked about their "favourite subject", participants identified "math" because it provided an appropriate level of challenge and because they held a belief that it had value.

I like Maths, I like that it's not easy but I'm good at it......it's [also] really important, like when you're older you need to be good at maths to work in a shop. (ASF School 1, baseline)

Similarly, participants identified "history" because it afforded choice and again, because they held a belief that it had value.

I like history... you can learn anything you want to learn about the past and... I think it's important... because if we don't know about the past, we'll just make the same mistakes and there will be more wars... (ASF School 2, baseline)

PE was identified as a favourite subject because it offered an appropriate level of challenge (i.e. offering a physical "break" from mental challenges in the classroom) and afforded opportunities for social interactions.

I think PE is probably my favourite... just because it's a break, it's not that stressful and you get to basically play with your friends. (TDM School 2, baseline)

Finally, when children were asked to identify their "favourite thing about school", responses were also identified as being underpinned by a combination of the same four themes, affordance of choice, appropriate level of challenge, importance of social interactions and belief that an experience was of value.

My favourite thing about school is probably seeing your friends and playing on the playground... learning new things and [feeling like] you're getting smarter...because things get easier. (Girl, ASF group, follow up)

All of it. Except getting up early. I hate having to get up early. But just, my teacher is really nice and we do fun things.....and you need to go to school to get smarter [otherwise] how are you going to get a job you like? (Boy, TDM group, follow up) 


\section{Discussion}

Beginning with measurement of PA, findings of this study suggest that participants attending TDM schools demonstrated significantly higher levels of PA in comparison to participants at ASF schools at baseline. This was not unexpected however, and likely represents the fact that TDM schools had already commenced the daily running initiative while ASF schools had only begun to address some early "success criteria". What is of note is that these results were not maintained over time. That is, participants in TDM schools demonstrated a significant decrease in PA levels from baseline to follow up (8 months later), while participants at ASF schools experienced an opposing trajectory and demonstrated a significant increase in PA levels over the same timeframe. Results relating to participants at TDM schools present as being in line with those of Breheny et al. (2020) who suggest that The Daily Mile initiative is beneficial in the immediate (i.e. within the first 4 - 6 months) but does not sustain interest (from either the teachers and/or children) over time. In contrast, PA benefits of participants at ASF schools were apparent at follow up. It is likely that the contrasting trajectories of PA levels for both groups can be explained by the contrasting PA initiatives participants were exposed to at each school i.e. the process-oriented ASF and outcome-oriented TDM. Each initiative had a distinctly contrasting implementation framework, i.e. a simplistic implementation process for TDM which supports more immediate "set-up" and thus, more immediate gains in PA levels, versus a more detailed process-oriented framework for ASF which takes time to embed and time for participants to reap rewards. Overall, while there was no significant difference in PA levels between groups at follow up, the trajectory experienced by ASF participants (a significant increase over time) presents as being more likely to support continued improvement in measured PA over time. Further measurement of the PA levels of both groups would provide a greater long term understanding of these trajectories (e.g. do ASF participants continue to improve; do TDM participants return to the high PA levels seen initially?) providing a more accurate account of the potential impact that ASF and TDM participation could have on PA behaviours over time.

Research indicates that in order for a school-based initiative to support lasting behavioural change, it should not only focus on increasing in-school PA levels, but also focus on positively impacting key modifiable determinants such as participant's perceptions and motivations towards PA engagement (Coulter \& Woods, 2011). Focus group results of the current study identified four emergent themes relating to participant perceptions of PA, PE and school, as well as their over-arching motivations towards PA engagement. These were: 1) Affordance of choice, 2) Appropriate level of challenge, 3) Importance of social interactions, and 4) A belief that an experience has value. Interestingly, these four themes very much align with the three basic psychological needs outlined by Self-Determination Theory (SDT) (Ryan \& Deci, 2000). In recent years, SDT has become a popular framework for evaluating children's enjoyment PA and motivations towards continued PA engagement (Fortier et al., 2012). As previously 
referenced, SDT underlines the importance of autonomy, the need to feel that engagement is relatively self-endorsed, personally important, and of value. This aligns with the identified themes of "affordance of choice" and "a belief that an experience has value". Next, SDT refers to competence, which among other things, refers to a need to feel capable and confident in doing all of the things expected of you. This aligns with the identified theme "appropriate level of challenge". Finally, SDT refers to the importance of relatedness, which includes the need to interact and have meaningful relationships with other people. This aligns with the identified theme "importance of social interactions". In an applied sense, SDT suggests that in order for participants to experience positive perceptions of enjoyment and motivations towards continued engagement in PA over time, three basic psychological needs relating to autonomy, competence and relatedness must be met.

Qualitative results at baseline suggest that these basic psychological needs were potentially met for some but certainly not all participants at both ASF and TDM schools. That is, the four themes were discussed as having both a positive and negative impact on participant's perceptions and experiences of PA, PE and school. For example, many participants discussed not being afforded choice ("I don't like [PE]...we have to do the running, you don't actually have a choice") and consequently identified as having negative perceptions of PE, predicting negative perceptions of PA engagement. Conversely, other participants who described being afforded choice ("I like [PE]... when it's up to the class to pick the activity") were identified as having more positive perceptions of enjoyment towards PE and PA engagement. An appropriate level of challenge was also discussed by participants with both positive ("it's not easy, but I'm good at it") and negative ("it was basically too easy....so I quit") repercussions for perceptions of enjoyment towards PA, PE and school. Similarly, social environmental factors such as relationships with peers and teachers also had both positive ("you can play with [your] friends and have fun"), and negative ("when no one picks you and you feel stressed") impact.

At follow up however, a clear difference between ASF and TDM participants was identified. "Belief that an experience has value" became strongly identified for the ASF group but was not present for TDM participants. That is, ASF participants articulated aknowledge and understanding relating to how, why and when to be active. This knowledge and understanding presented as underpinning a belief that PE was of value ("[you] learn how to check your heartbeat...your pulse.... and get to know your muscles"), and a belief that PA was of value ("you get the sun on your face and that gives you vitamins and it's good for me") suggesting positive repercussions for participant perceptions and motivations towards PA engagement. To that end, our findings suggest that the basic psychological needs associated with SDT were more strongly met by participants at ASF schools in comparison to participants at TDM schools. That is, when discussing PA, PE and school, ASF participants mostly described affordance of choice, level of challenge and social interactions in positive terms. Conversely, more TDM participants discussed an absence of choice, inappropriate level of challenge and, 
to a lesser extent, negative interactions with peers as well as teachers.

Accordingly, qualitative results in this study suggest that a process-oriented PA initiative (ASF) met the psychological needs of more children, promoting more positive perceptions of enjoyment and motivations toward PA engagement. This finding is perhaps best evidenced in the response of an ASF participant who referenced a combination of autonomy, relatedness and competence when describing their "favourite thing about school"; the ASF playground activities.

"The best thing about school is probably our playground... We have lots of [stations]... and you get to play things that you want to play... like you're never really left out... when you go back to class you feel like you've had a good bit of exercise".

In contrast, an outcome-oriented PA initiative (TDM) was identified as being less effective at meeting participant's basic psychological needs, with mixed perceptions of enjoyment and motivations towards PA engagement identified across the research period. As a result, evidence from teachers at ASF schools stating that ASF participation facilitated increased enjoyment in PA experiences and an increased understanding of why being active is important (McGann et al., 2020), can be corroborated by the current study. Conversely, statements in TDM literature suggesting that the initiative "encourages children to be aware of their health" and that "all children enjoy it and participate happily" (The Daily Mile UK, 2020) could not be supported. Moreover, this study concurs with Daly-Smith et al. (2019) who suggest that TDM participation facilitates improved physical outcomes in some children but not all, and extends this finding to suggest that basic psychological needs required to support positive perceptions of enjoyment and motivations towards PA engagement were also met by some TDM participants but certainly not all.

With that said, research by Love, Adams, \& van Sluijs (2019) proposes that we can only account for the effectiveness of a school-based initiative when it is implemented with fidelity. Both initiatives evaluated in this study have sophisticated websites and well-presented literature to support the implementation process. ASF schools are expected to follow explicit criteria across the school year and demonstrate that these criteria have been met to "accreditors" during an official school visit (The Active School Flag, 2020). In contrast, TDM implementation has less rigid requirements, with the outcome of completing the "daily mile" being championed above all else. This "simplicity" of implementation is promoted by The Daily Mile Foundation as a significant selling point. However, a less rigid structure, while appealing to the schools, can have unintended negative consequences. For example, at one TDM school in the current study, participant comments such as "most of the time we don't do the normal PE because ...we have to do our [Daily Mile]", and "if you slow down, teacher shouts at you", emphasise that TDM is open to being implemented in a way that is not intended. This is supported by Hanckel et al. (2019) who reported that of the 69 TDM schools participating in their study, each one implemented the initiative in a dif- 
ferent way. It has been reported that The Daily Mile Foundation are in the process of adapting their information materials and resourcing "co-ordinators" to assist with implementation fidelity, in order to ensure that engagement with the initiative results in the intended benefits (Hanckel et al., 2019).

In contrast, ASF implementation is guided by a detailed structure focused on a range of "success criteria" across the areas of whole-school evaluation, provision of quality PE, co-curricular opportunities for PA and partnerships. In this sense the "process" of achieving the "Active School Flag" is championed above any outcome (for example definitive minutes or distances of movement). ASF implementation fidelity is not only supported by "success criteria", but also by regular meetings for coordinators, regular contact from the ASF committee and visits to the school from ASF accreditors. Ni Chróinín et al. (2012) suggest that the detailed structure of ASF supports development and change in the provision of PA for children, which is also supported in part by the recent publication by McGann et al. (2020). Findings of this current study add further credence to this claim, but also highlight the importance of the supports and structure that ASF offer schools to assist with implementation fidelity. We propose that this represents a potential "recipe" for success that is worth further research and investigation.

Interestingly, one "ingredient" of the ASF outlined in "success criteria" explicitly points schools towards participation in a "running initiative" (which could include TDM) (The Active School Flag, 2020). While neither of the ASF schools in this study implemented a running initiative during the research period, we propose that an initiative like TDM, as a spoke in the hub of a process-driven initiative, could have real merit and impact. Indeed, the concept of an outcome-oriented initiative (such as TDM) implemented as part of an overarching process-oriented initiative (such as ASF), presents as an ideal way to directly increase PA levels, while also supporting the basic psychological needs required for sustaining meaningful change in the longer term.

\section{Conclusion}

The school setting has been identified as a key place to tackle low levels of PA in children. Conversely, recent literature suggests that in order to bring about a lasting change in movement behaviours, school-based PA initiatives should not only look at increasing measured PA but also meet basic psychological needs required to foster positive perceptions of enjoyment and motivations towards continued engagement in PA beyond the school setting. If we consider an old expression, "It's not what you do, it's the way that you do it", results of this study suggest that from the perspective of measured PA levels in the school setting, "what" we do (ASF or TDM) may not be as important as we think. That is, both initiatives outlined in this study supported similar levels of PA at follow up. However, when it comes to positively supporting psychological outcomes deemed crucial to motivate children towards sustained PA engagement and lasting behavioural change, then the "way" that we approach PA (e.g. a process- or outcome-oriented approach) could have significant impact. 


\section{Acknowledgements}

The authors would like to thank the principals and pupils of the schools who participated in this study.

\section{Conflicts of Interest}

The authors declare no conflicts of interest regarding the publication of this paper.

\section{References}

Barnett, T. A., Kelly, A. S., Young, D. R., Perry, C. K., Pratt, C. A., Edwards, N. M. et al. (2018). Sedentary Behaviors in Today's Youth: Approaches to the Prevention and Management of Childhood Obesity: A Scientific Statement from the American Heart Association. Circulation, 138, e142-e159. https://doi.org/10.1161/CIR.0000000000000591

Basham, R. B. (1986). Scientific and Practical Advantages of Comparative Design in Psychotherapy Outcome Research. Journal of Consulting and Clinical Psychology, 54, 88-94. https://doi.org/10.1037/0022-006X.54.1.88

Braun, V., \& Clarke, V. (2006). Using Thematic Analysis in Psychology. Qualitative Research in Psychology, 3, 77-101. https://doi.org/10.1191/1478088706qp063oa

Braun, V., \& Clarke, V. (2019). Reflecting on Reflexive Thematic Analysis. Qualitative Research in Sport, Exercise and Health, 11, 589-597.

https://doi.org/10.1080/2159676X.2019.1628806

Breheny, K., Passmore, S., Adab, P., Martin, J., Hemming, K., Lancashire, E. R. et al. (2020). Effectiveness and Cost-Effectiveness of the Daily Mile on Childhood Weight Outcomes and Wellbeing: A Cluster Randomised Controlled Trial. International Journal of Obesity, 44, 812-822. https://doi.org/10.1038/s41366-019-0511-0

Cain, K. L., Sallis, J. F., Conway, T. L., Van Dyck, D., \& Calhoon, L. (2013). Using Accelerometers in Youth Physical Activity Studies: A Review of Methods. Journal of Physical Activity and Health, 10, 437-450. https://doi.org/10.1123/jpah.10.3.437

Chalkley, A., Routen, A., Harris, J., Cale, L., Gorely, T., \& Sherar, L. (2018). A Retrospective Qualitative Evaluation of Barriers and Facilitators to the Implementation of a School-Based Running Programme. BMC Public Health, 18, Article No. 1189. https://doi.org/10.1186/s12889-018-6078-1

Chesham, R. A., Booth, J. N., Sweeney, E. L., Ryde, G. C., Gorely, T., Brooks, N. E. et al. (2018). The Daily Mile Makes Primary School Children More Active, Less Sedentary and Improves Their Fitness and Body Composition: A Quasi-Experimental Pilot Study. BMC Medicine, 16, 64. https://doi.org/10.1186/s12916-018-1049-z

Coulter, M., \& Woods, C. B. (2011). An Exploration of Children's Perceptions and Enjoyment of School-Based Physical Activity and Physical Education. Journal of Physical Activity and Health, 8, 645-654. https://doi.org/10.1123/jpah.8.5.645

Daly-Smith, A., Morris, J. L., Hobbs, M., \& McKenna, J. (2019). Commentary on a Recent Article on the Effects of the "Daily Mile" on Physical Activity, Fitness and Body Composition: Addressing Key Limitations. BMC Medicine, 17, 96.

https://doi.org/10.1186/s12916-019-1335-4

Department of Health and Social Care (2018). Childhood Obesity: A Plan for Action, Chapter 2.

https://assets.publishing.service.gov.uk/government/uploads/system/uploads/attachme nt data/file/718903/childhood-obesity-a-plan-for-action-chapter-2.pdf 
Evenson, K. R., Catellier, D. J., Gill, K., Ondrak, K. S., \& McMurray, R. G. (2008). Calibration of Two Objective Measures of Physical Activity for Children. Journal of Sports Sciences, 26, 1557-1565. https://doi.org/10.1080/02640410802334196

Fortier, M. S., Duda, J. L., Guerin, E., \& Teixeira, P. J. (2012). Promoting Physical Activity: Development and Testing of Self-Determination Theory-Based Interventions. International Journal of Behavioral Nutrition and Physical Activity, 9, 20. https://doi.org/10.1186/1479-5868-9-20

Grove, R., Zillich, I., \& Medic, N. (2014). A Process-Oriented Measure of Habit Strength for Moderate-to-Vigorous Physical Activity. Health Psychology and Behavioral Medicine: An Open Access Journal, 2, 379-389. https://doi.org/10.1080/21642850.2014.896743

Hanckel, B., Ruta, D., Scott, G., Peacock, J. L., \& Green, J. (2019). The Daily Mile as a Public Health Intervention: A Rapid Ethnographic Assessment of Uptake and Implementation in South London, UK. BMC Public Health, 19, Article No. 1167.

https://doi.org/10.1186/s12889-019-7511-9

Hänggi, J. M., Phillips, L. R., \& Rowlands, A. V. (2013). Validation of the GT3X ActiGraph in Children and Comparison with the GT1M ActiGraph. Journal of Science and Medicine in Sport, 16, 40-44. https://doi.org/10.1016/j.jsams.2012.05.012

Kim, Y., Beets, M. W., \& Welk, G. J. (2012). Everything You Wanted to Know about Selecting the "Right" Actigraph Accelerometer Cut-Points for Youth, But...: A Systematic Review. Journal of Science and Medicine in Sport, 15, 311-321. https://doi.org/10.1016/j.jsams.2011.12.001

Love, R., Adams, J., \& van Sluijs, E. (2019). Are School-Based Physical Activity Interventions Effective and Equitable? A Meta-Analysis of Cluster Randomized Controlled Trials with Accelerometer-Assessed Activity. Obesity Reviews, 20, 859-870. https://doi.org/10.1111/obr.12823

Love, R., Adams, J., Atkin, A., \& van Sluijs, E. (2019). Socioeconomic and Ethnic Differences in Children's Vigorous Intensity Physical Activity: A Cross-Sectional Analysis of the UK Millennium Cohort Study. BMJ Open, 9, e027627.

https://doi.org/10.1136/bmjopen-2018-027627

McGann, J., Meegan, S., Duff, C., Woods, C., Murtagh, E., \& Belton, S. (2020). Teacher Experiences Implementing the "Active School Flag" Initiative to Support Physically Active School Communities in Ireland. Irish Educational Studies.

https://doi.org/10.1080/03323315.2020.1794926

NHS (2018). Health Survey for England.

https://digital.nhs.uk/data-and-information/publications/statistical/health-survey-for-e ngland

Ni Chróinín, D., Murtagh, E., \& Bowles, R. (2012). Flying the “Active School Flag”: Physical Activity Promotion through Self-Evaluation in Primary Schools in Ireland. Irish Educational Studies, 31, 281-296. https://doi.org/10.1080/03323315.2012.710066

Proudfoot, N. A., King-Dowling, S., Cairney, J., Bray, S. R., MacDonald, M. J., \& Timmons, B. W. (2019). Physical Activity and Trajectories of Cardiovascular Health Indicators during Early Childhood. Pediatrics, 144, e20182242.

https://doi.org/10.1542/peds.2018-2242

Ryan, R. M., \& Deci, E. L. (2000). Self-Determination Theory and the Facilitation of Intrinsic Motivation, Social Development, and Well-Being. American Psychologist, 55, 68-78. https://doi.org/10.1037/0003-066X.55.1.68

Ryan, R. M., \& Deci, E. L. (2011). A Self-Determination Theory Perspective on Social, Institutional, Cultural, and Economic Supports for Autonomy and Their Importance for 
Well-Being. In V. I. Chirkov, R. M. Ryan, \& K. M. Sheldon (Eds.), Cross-Cultural Advancements in Positive Psychology (Vol. 1., pp. 45-64). Dordrecht: Springer Science + Business Media. https://doi.org/10.1007/978-90-481-9667-8 3

Sasaki, J. E., John, D., \& Freedson, P. S. (2011). Validation and Comparison of ActiGraph Activity Monitors. Journal of Science and Medicine in Sport, 14, 411-416.

https://doi.org/10.1016/j.jsams.2011.04.003

The Active School Flag (2020). https://activeschoolflag.ie

The Daily Mile UK (2020). https://thedailymile.co.uk

Woods, C., Powell, C., Saunders, J. A., O’Brien, W., Murphy, M. H., Duff, C. et al. (2018). The Children's Sport Participation and Physical Activity Study (CSPPA 2018). https://www.sportireland.ie/sites/default/files/2019-10/csppa-2018-final-report 1.pdf

World Health Organisation (2011). Global Strategy on Diet, Physical Activity and Health. https://www.who.int/dietphysicalactivity/pa/en

Yli-Piipari, S., Kulmala, J. S., Jaakkola, T., Hakonen, H., Fish, J. C., \& Tammelin, T. (2016). Objectively Measured School Day Physical Activity among Elementary Students in the United States and Finland. Journal of Physical Activity and Health, 13, 440-446. https://doi.org/10.1123/jpah.2015-0335 